\title{
Molecular footprints of selection effects and whole genome duplication (WGD) events in three blueberry species: detected by transcriptome dataset
}

\author{
Yunsheng Wang ${ }^{1 *+}\left(\mathbb{D}\right.$, Fei $\mathrm{Nie}^{2+}$, Muhammad Qasim Shahid ${ }^{3,4,5+}$ (D) and Faheem Shehzad Baloch ${ }^{6}$
}

\begin{abstract}
Background: Both selection effects and whole genome duplication played very important roles in plant speciation and evolution, and to decipher the corresponding molecular footprint has always been a central task of geneticists. Vaccinium is species rich genus that comprised of about 450 species, and blueberry is one of the most important species of Vaccinium genus, which is gaining popularity because of high healthful value. In this article, we aimed to decipher the molecular footprints of natural selection on the single copy genes and WGD events occur in the evolutionary history of blueberry species.
\end{abstract}

Results: We identified 30,143, 29,922 and 28,891 putative protein coding sequences from 45,535, 42,914 and 43,630 unigenes assembled from the leaves' transcriptome assembly of 19 rabbiteye (T1), 13 southern highbush (T2) and 22 northern highbush (T3) blueberry cultivars. A total of 17, 21 and 27 single copy orthologs were found to undergone positive selection in $T 1$ versus $T 2, T 1$ versus $T 3$, and $T 2$ versus $T 3$, respectively, and these orthologs were enriched in metabolic pathways including "Terpenoid backbone biosynthesis", "Valine, leucine and isoleucine biosynthesis", "Butanoate metabolism", "C5-Branched dibasic acid metabolism" "Pantothenate and CoA biosynthesis". We also detected significant molecular footprints of a recent (about 9.04 MYA), medium (about 43.44 MYA) and an ancient (about 116.39 MYA) WGD events that occurred in the evolutionary history of three blueberry species.

Conclusion: Some important functional genes revealed positive selection effect in blueberry. At least three rounds of WGD events were detected in the evolutionary history of blueberry species. Our work provides insights about the genetic mechanism of adaptive evolution in blueberry and species radiation of Vaccinium in short geological scale time.

Keywords: Adaptive evolution, Phylogenetic analysis, Polyploid, Unigene, Vaccinium

\footnotetext{
*Correspondence: wys3269@126.com

†Yunsheng Wang, Fei Nie and Muhammad Qasim Shahid contributed equally to this work.

${ }^{1}$ College of Health and Life Science, Kaili University, Kaili City 556011,

Guizhou Province, China

Full list of author information is available at the end of the article
}

C C The Author(s). 2020 Open Access This article is licensed under a Creative Commons Attribution 4.0 International License, which permits use, sharing, adaptation, distribution and reproduction in any medium or format, as long as you give appropriate credit to the original author(s) and the source, provide a link to the Creative Commons licence, and indicate if changes were made. The images or other third party material in this article are included in the article's Creative Commons licence, unless indicated otherwise in a credit line to the material. If material is not included in the article's Creative Commons licence and your intended use is not permitted by statutory regulation or exceeds the permitted use, you will need to obtain permission directly from the copyright holder. To view a copy of this licence, visit http://creativecommons.org/licenses/by/4.0/ The Creative Commons Public Domain Dedication waiver (http://creativecommons.org/publicdomain/zero/1.0/) applies to the data made available in this article, unless otherwise stated in a credit line to the data. 


\section{Background}

Mutation-selection process is the most fundamental mechanism of evolution, the mutations are the source on which natural selection operates and eventually natural selection lead to an optimization process of allele (mutant) frequencies [1]. Identifying alleles or genes influenced by natural selection have fascinated the geneticists for a long time $[2,3]$. So far, more than ten statistical methods have been introduced to detect the molecular footprints that resulted in natural selection $[4,5]$. Of these, the method of $\mathrm{Ka} / \mathrm{Ks}$ ratio (Ka: the number of non-synonymous substitutions per non-synonymous site, and Ks: the number of synonymous nucleotide substitutions per synonymous site) has a great impact on estimation of selection pressure and understanding the evolutionary dynamics of proteincoding sequences across closely related and yet diverged species [6-8].

Whole genome duplication (WGD) or polyploidization event is another evolutionary genetic phenomenon that has long fascinated geneticists for its great significance in speciation and evolution [9-12]. For example, WGD event is an important force for the species radiations of many plant lineages [13-17]. According to the age and outcomes of cytogenetics and karyotype, WGD events can be classified into two kinds, one is the recent or new polyploidization event, which results in "autopolyploids" and emerge from the fusion of gametes produced by non-meiosis, or hybridization of normal meiosis gametes of same species individuals, or "allopolyploids" produced from inter-specific hybridization [18]. About $47-70 \%$ of angiosperm species are estimated as polyploid and approximately $25 \%$ of vascular plants have undergone recent polyploidization $[19,20]$, and this WGD event could be detected by karyotyping and flow cytometry method [21]. Another is the ancient polyploidization event, which happened in earlier geological ages. It is believed that all existing angiosperms are paleopolyploids, and have undergone two or more rounds of ancient polyploidization events in their evolutionary history [22, 23]. In spite of subsequent diploidization (massive gene loss and structural rearrangements) or fractionation events occur and made the polyploidy return to a diploid state, the footprint of ancient WGD would still be detected in genome sequence in the form of blocks of duplicated genes [24, 25].

High-throughput genome data produced by nextgeneration sequencing technology is being used frequently to investigate the key issues of evolutionary genetics [26-28]. However, full genome sequencing remained impractical for some non-model species with polyploid genome, high heterozygosity or high GC contents in the genome. In such cases, transcriptome sequencing provides ideal alternative with the advantages including sequencing cost, rich in information, coding protein, functional prediction, and no species or individual restrictions [29-31]. The transcriptome sequencing has been widely used for detection of molecular footprints of evolutionary studies including selection effect and WGD in recent years [32-36].

Vaccinium is a young and widespread genus in Ericaceae, and contains about 450 species $[37,38]$. The species number of Vaccinium genus is far more than average species number in plant at genus level (about 67 per genus) and in Ericaceae (about 80 per genus) (http://www.theplantlist. org/statistics/). Obviously, the Vaccinium species had undergone a recent and evolutionary radiation. In recent decades, the Vaccinium species have attracted more and more attentions for high antioxidant contents in fruit of many species (e.g. blueberries, cranberries, bilberry, and lingonberry) that have nutritional and therapeutic effects [39]. Blueberry is one of the most important flora of $\mathrm{Vacci}$ nium, which is composed of about 20 species [38]. Beside six diploid species, all blueberry species are polyploid, and some have complex polyploid genome, such as Vaccinium corymbosum [40]. Despite of only one century history of domestication and cultivation, blueberry has been listed in the top five economically important, non-citrus fruits in North America [41, 42]. The main reason for the popularity of blueberry is its excellent dietary therapy functions that produced from high anthocyanins contents in fruits [30, 43-45]. The current commercially planting blueberry varieties are principally derived from diploid lowbush blueberry ( $V$. myrtilloides), tetraploid lowbush blueberry ( $V$. angustifolium), northern tetraploid highbush blueberry ( $V$. corymbosum), hexaploid rabbiteye blueberry ( $V$. virgatum), southern highbush blueberry (hybrid from $V$. corymbosum $L \times$ native southern species) and semi-highbush blueberry (hybrid from $V$. corymbosum $\times V$. angustifolium) [46, 47]. Among them, rabbiteye, northern highbush, and southern highbush blueberries are widely planted at commercial level.

Until now, like many important crops, blueberry research has entered the genome era. For example, the genome draft of a northern high-bush blueberry has been published [48, 49]. The transcriptome analyses have been used for blueberry studies about characteristics of gene expression in the cold environment [50-52], the metabolics related genes of blueberry antioxidant substances [53], the changes of gene expression profiles in blueberry after infection with Colletotrichum acutatum [54], the gene expression dynamics during five blueberry fruit development stages [48], and detection of molecular markers [55]. However, the reports about the genome evolution of blueberry are limited. In this article, we analyzed the assembled transcriptome data, which was generated from second generation sequencing platform, and the major aims were to (1) re-construct the phylogenetic relationship among 54 blueberry cultivars, 
(2) identify the genes undergone selection effect, (3) and to detect the WGD event in the evolutionary history of blueberry, and provide insights on the genetic mechanism about evolutionary radiation of Vaccinium species.

\section{Results}

\section{Summary of protein coding unigenes}

From 45,535 assembled unigenes in rabbiteye blueberry (T1), 42,914 in southern highbush blueberry (T2) and 43,630 in northern highbush blueberry (T3) species, we identified 30,143, 29,922 and 28,891 protein coding unigenes according to the annotation of Nr, Swiss-Prot, GO and KEGG databases, and by using program ESTScan in three blueberry species, respectively (Table 1).

\section{Gene families' statistics}

We detected 45,171 genes families from protein coding unigenes of three blueberry transcriptomes. Of these, 14, 882 gene families, including 52,780 unigenes, were shared by all three blueberry transcriptomes. In total, 1643 gene families, including 3306 unigenes were shared between rabbiteye and southern highbush blueberry, 2360 gene families including 4780 unigenes were shared by southern highbush and northern highbush blueberry, and 1585 gene families including 3215 unigenes were common between rabbiteye and northern highbush blueberry. A total of 9395 gene families including 9421 unigenes, 8162 gene families including 8188 unigenes, and 7144 gene families including 7266 unigenes were specific to rabbiteye, southern highbush and northern highbush blueberry species, respectively. We also identified 12,688 homologous single copy gene families (orthologs) and 2915 multi-copy gene families shared by all three blueberry species (Table 2; Fig. 1).

\section{Genetic relationships among blueberry cultivars}

In the phylogenetic tree, all the cultivars clustered into two main groups, the rabbiteye cultivars grouped into a main group, and southern highbush and northern highbush blueberry cultivars clustered into another main group, and then separated into two large groups having same kind of blueberry in a group. In rabbiteye group, which was comprised of 19 cultivars, the sample V.asch01 (Cultivar:Bluebell) and
V.asch08 (Cultivar:Summit) were far away from other cultivars in the genetic distance or phylogenetic relationship, and V.asch09 (Cultivar:Delite), V.asch17 (Cultivar:Climax), V.asch19 (Cultivar:Bonita), V.asch13 (Cultivars Bluebelle), V.asch 18 (Cultivar:Beckyblue) were relatively close, and the other cultivars have relatively close phylogenetic relationship with each other. In the southern highbush group of 13 cultivars, V.cory01 (Cultivar:Sharpblue), V.cory07 (Cultivar:O'Neal) and V.cory06 (Cultivar:Misty) located at the bottom of the phylogenetic tree, and showed a farther kinship. In the northern highbush group of 22 cultivars, the V.cory30 (Cultivar:Earliblur) was located at the bottom of cluster, and V.cory15 (Cultivar:Sierra), V.cory22 (Cultivar: Big-bluegold), V.cory21 (Cultivar:Brigitta), V.cory23 (Cultivar:Collins), V.cory18 (Cultivar:Bluehaven), V.cory20 (Cultivar:Legacy), V.cory24 (Cultivar: Blueray) and V.cory26 (Cultivar: Jersey) clustered into a major branch with relatively close affinity, and all other cultivars assembled into another major branch, which have relatively close phylogenetic relationship (Fig. 2).

\section{Selection effect of single copy homologous unigenes}

Of the 12,688 single copy orthologs in three blueberry species, 2276, 2452, 1711 orthologs were detected in T1 versus T2, T1 versus T3 and T2 versus T3 after filtering with Ks $>0.1$ and applicable Ka and Ks. Among them, 13, 15 and 10 orthologs showed significant footprints of strong positive selection $(\mathrm{Ka} / \mathrm{Ks}>1) ; 4,6$ and 7 orthologs $\mathrm{Ka} / \mathrm{Ks}$ values were $0.5<\mathrm{Ka} / \mathrm{Ks}<1$, which displayed the footprints of weak positive selection; 684, 721 and 512 orthologs $\mathrm{Ka} / \mathrm{Ks}$ showed the footprints of purifying selection $(\mathrm{Ka} / \mathrm{Ks}<0.1) ; 1575,1710$ and 1180 orthologs exhibited neutral evolution with $\mathrm{Ka} / \mathrm{Ks}$ between $0.1 \sim 0.5$ in three groups (Table 3; Fig. 3; Table S1). In total, 32 unigenes in T1, 31 unigenes in $\mathrm{T} 2$ and 37 unigenes in T3 were identified to undergo positive selection (Table 4; Table S2). Of these positive selective unigenes, nine unigenes in T1 produced $91 \mathrm{GO}$ terms (62 GO terms were associated with biological process, $18 \mathrm{GO}$ terms with cellular component and $11 \mathrm{GO}$ terms with molecular function). Among them, four GO terms (GO:0016772, GO:0010506, GO:0031329 and GO:0009894) were found to be significantly enriched. A total of 10 unigenes in T2

Table 1 The number of protein coding unigenes detected from the total assembled transcripts of 54 cultivars of three blueberry species

\begin{tabular}{lllll}
\hline Code & $\begin{array}{l}\text { Total number } \\
\text { of transcripts }\end{array}$ & $\begin{array}{l}\text { Total number of transcripts } \\
\text { annotated by at least one of } \\
\text { Nr, Swiss-Prot, GO and KEGG }\end{array}$ & $\begin{array}{l}\text { Total number of transcripts } \\
\text { predicted by ESTScan }\end{array}$ & $\begin{array}{l}\text { Total number of protein } \\
\text { coding transcript }\end{array}$ \\
\hline T1 & 45,535 & 28,091 & 2052 & 30,143 \\
T2 & 42,914 & 28,115 & 1807 & 29,922 \\
T3 & 43,630 & 27,256 & 1635 & 28,891 \\
\hline
\end{tabular}

$\mathrm{T} 1, \mathrm{~T} 2$ and $\mathrm{T} 3$ indicate rabbiteye ( $V$. virgatum), southern highbush ( $V$. corymbosum $\times$ southern species), and northern highbush blueberry ( $V$. corymbosum) species, respectively 
Table 2 Summary of gene families detected in three blueberry species

\begin{tabular}{llllll}
\hline Species & $\begin{array}{l}\text { Coding of } \\
\text { protein gene }\end{array}$ & $\begin{array}{l}\text { Gene } \\
\text { families }\end{array}$ & $\begin{array}{l}\text { Specific } \\
\text { gene }\end{array}$ & $\begin{array}{l}\text { Single copy } \\
\text { gene families }\end{array}$ & $\begin{array}{l}\text { Multi-copy } \\
\text { homologous } \\
\text { genes }\end{array}$ \\
\hline T1 & 30,143 & 9395 & 9421 & 9371 & 24 \\
T2 & 29,922 & 8162 & 8188 & 8136 & 26 \\
T3 & 28,891 & 7144 & 7266 & 7028 & 115 \\
T1,T2 & NA & 1643 & 3306 & 1625 & 18 \\
T1,T3 & NA & 1585 & 3215 & 1546 & 39 \\
T2,T3 & NA & 2360 & 4780 & 2308 & 52 \\
T1,T2,T3 & NA & 14,882 & 52,780 & 12,688 & 2195 \\
Total & 88,956 & 45,171 & 88,956 & 42,702 & 2469 \\
\hline
\end{tabular}

$\mathrm{T} 1, \mathrm{~T} 2$ and $\mathrm{T} 3$ indicate rabbiteye ( $V$. virgatum), southern highbush ( $V$. corymbosum $\times$ southern species), and northern highbush blueberry $(V$. corymbosum) species, respectively

NA Not applicable

produced $185 \mathrm{GO}$ terms (98 GO terms were related to biological process, $39 \mathrm{GO}$ terms with cellular component and $48 \mathrm{GO}$ terms with molecular function). Of these, 8 GO terms (GO:0010506, GO:0031329, GO:0009894, GO: 0010506, GO:0031329, GO:0016485, GO:0051604 and GO:0009894) were found to be significantly enriched. Fourteen unigenes in T3 produced 234 GO terms (135 GO terms were associated with biological process, 38 GO terms with cellular component and 61 GO terms with molecular function). Among them, six GO terms (GO:0016744, GO:0010506, GO:0031329, GO:0009894,

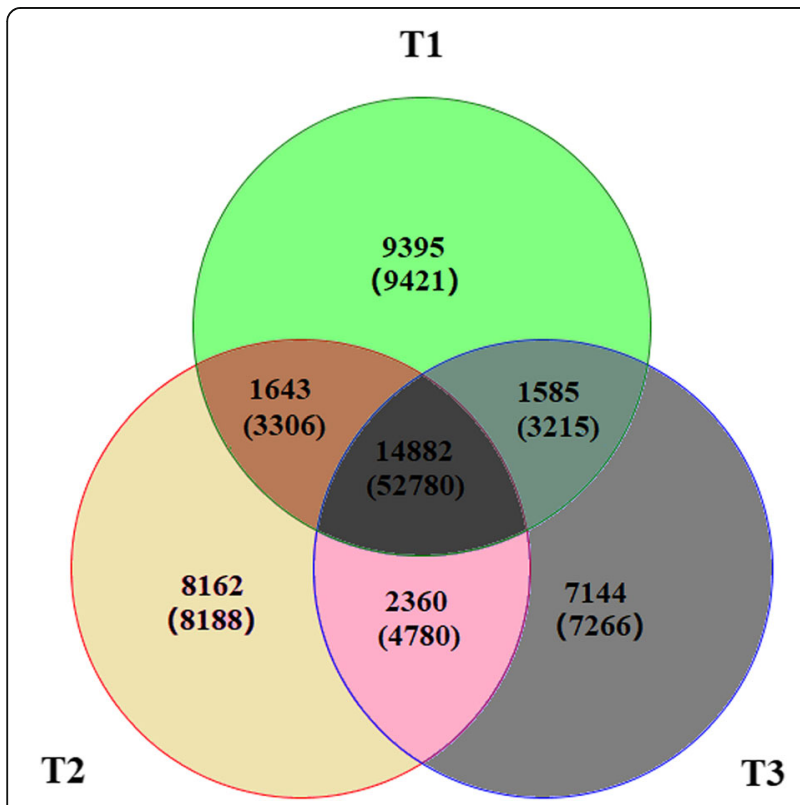

Fig. 1 Venn analysis of gene families in three blueberry species. T1, $\mathrm{T} 2$ and $\mathrm{T} 3$ indicate rabbiteye ( $\mathrm{V}$. virgatum), southern highbush ( $\mathrm{V}$. corymbosum $\times$ southern species), and northern highbush blueberry (V. corymbosum) species, respectively. The numbers without parenthesis represent the gene families, and the number in parenthesis represent the genes number
GO:0016485 and GO:0051604) were found to be significantly enriched (Table 4 Table S3). Of positive selective unigenes, eight unigenes were annotated by KEGG database, T1Unigene0035236 and T3-Unigene0033665, T2-Unigene00 00660 and T3-Unigene0000319, T2-Unigene0021375 and T3-Unigene0020145, and T2-Unigene0023454 and T3-Unig ene002102 were orthologous pairs. Among them, T2-Unige ne0023454 and T3-Unigene002102 were the putative gene encoding "Ste24 endopeptidase" whose ID was 3.4.24.84 in KEGG database, and "Ste24 endopeptidase" is a key enzyme involving the metabolic pathway of "Terpenoid backbone biosynthesis" whose ID was ko00900 in KEGG. T1-Unigene0035236 and T3-Unigene0033665 were the putative genes encoding "Acetolactate synthase" whose ID was 2.1.1.6 in KEGG database, and Acetolactate synthase is a key enzyme of multi-pathways such as "Valine, leucine and isoleucine biosynthesis (Ko00290)", "Butanoate metabolism (Ko00650)", "C5-Branched dibasic acid metabolism (Ko00660)" "Pantothenate and CoA biosynthesis (Ko00770)", and these pathways were hit by above two orthologous pairs and found to be significantly enriched (Table 4; Table S4). A total of 1119, 1047 and 1083 unigenes in T1, T2 and T3 were detected to undergo purifying selection by at least orthologous of one groups (T1 vs T2, T1 vs T3 and T2 vs T3), of which, 286, 149 and 150 unigenes in T1, T2 and $\mathrm{T} 3$ were found to be overlapped between $\mathrm{T} 1$ vs $\mathrm{T} 2$ and T1 vs T3 (Fig. 4a), T1 vs T2 and T2 vs T3 (Fig. 4b), and $\mathrm{T} 1$ vs $\mathrm{T} 3$ and $\mathrm{T} 2$ vs T3 (Fig. 4c), respectively.

Genome wide duplication events of three blueberry species Ks age distribution of paralogs in T1, T2 and T3 displayed three significant peaks conforming to the normal distribution with almost similar fitting curve. The first peak in three blueberry species were detected with a mode at $K s \approx 0.11$, and it represented a recent shared WGD event that happened about 9.02 million years ago 


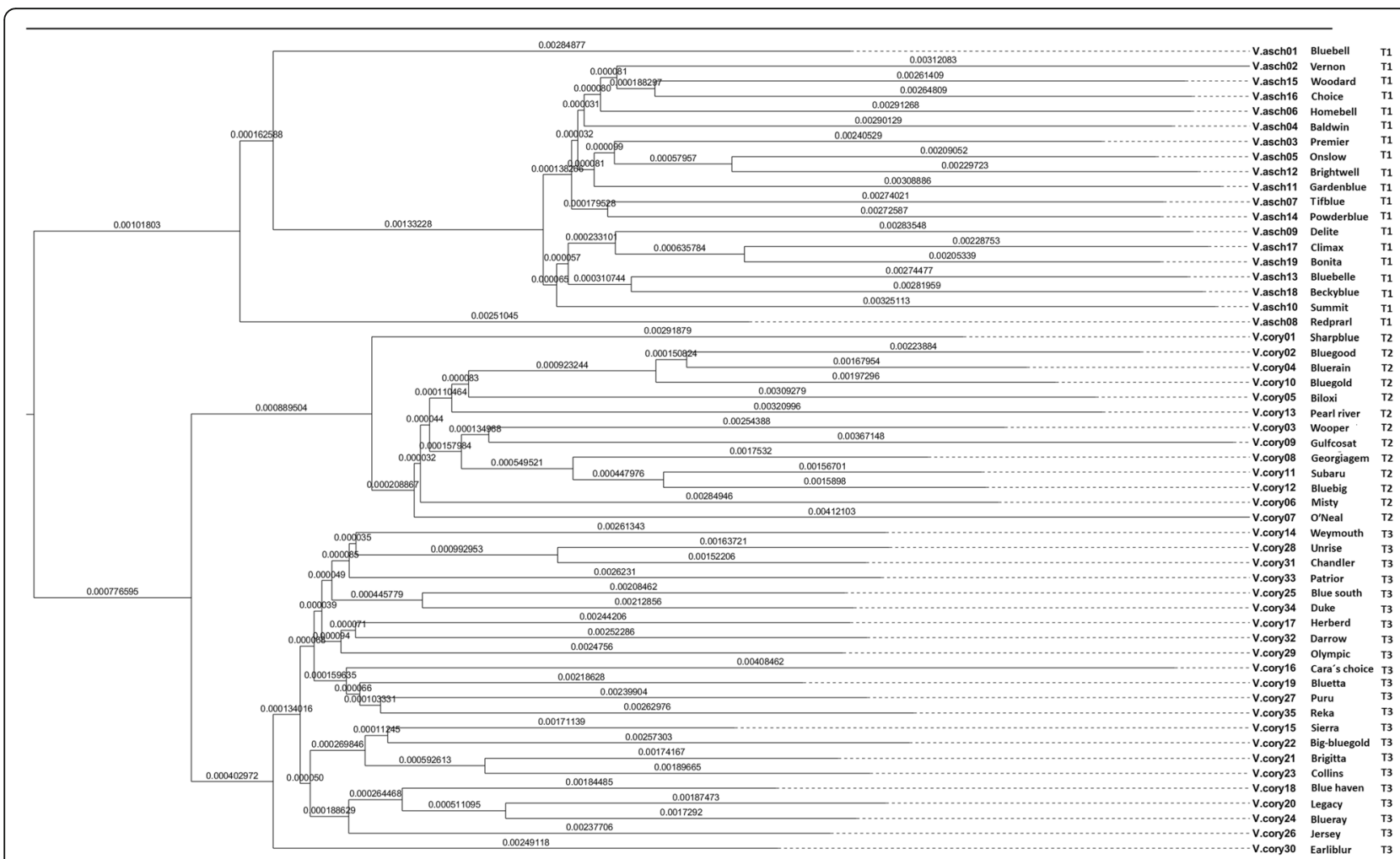

Fig. 2 Phylogenetic tree of 54 blueberry cultivars constructed by single copy unigenes. T1, T2 and T3 indicate rabbiteye $(V$. virgatum), southern highbush (V. corymbosum $\times$ southern species) and northern highbush blueberry (V. corymbosum) species, respectively

in the evolutionary history of three kinds of blueberry species. The second peak with a mode at $\mathrm{Ks} \approx 0.53$ in three blueberry species represented a medium shared WGD event that happened in the evolutionary history of three kinds of blueberry species about 43.44 million years ago. The third peak with a mode near at $\mathrm{Ks} \approx 1.42$ in three blueberry species indicated an ancient shared WGD event in the evolutionary history of three different species of blueberry about 116.39 million years ago. Among three peaks, the recent peak of Ks age distribution was thinnest for the smallest variability of normal distribution, while the third one was the thickest for the biggest variability of normal distribution, and this trend was in accordance with the evolutionary dynamics of subsequent diploidization of WGD events (Fig. 5, Table 5).

\section{Discussion}

Genetic relationships among blueberry cultivars

Clarifying the genetic or phylogenetic relationships among organisms are greatly helpful for parent selection in breeding projects [56]. In the last three decades, the molecular markers such as RAPD, AFLP, SSR, SNP have played an important role to study the phylogenetic relationship of individuals among intra- and inter-species $[57,58]$. In the genome era, large scale SNP data have been developed by using next-generation high throughput sequencing technologies at unprecedented speed $[59,60]$, and this makes SNP markers the most frequent and convenient tool to study phylogenetic relationship of organisms [61, 62]. Besides above molecular markers, the single copy orthologues genes also regarded as

Table $3 \mathrm{Ka} / \mathrm{Ks}$ test statistics of single copy orthologs number in three blueberry species

\begin{tabular}{|c|c|c|c|c|c|c|c|}
\hline Species 1 & Species 2 & $\begin{array}{l}\text { Total single copy } \\
\text { Orthologous } \\
\text { pairs }\end{array}$ & $\begin{array}{l}\text { Filtered Orthologous } \\
\text { pairs with } \mathrm{Ks}>0.1 \text { and } \\
\text { applicable Ks or Ka }\end{array}$ & $\begin{array}{l}\text { Orthologous pairs } \\
\text { with } \mathrm{Ka} / \mathrm{Ks}>1\end{array}$ & $\begin{array}{l}\text { Orthologous pairs } \\
\text { with } 0.5>\mathrm{Ka} / \mathrm{Ks}>1\end{array}$ & $\begin{array}{l}\text { Orthologous pairs } \\
\text { with } 0.1>\mathrm{Ka} / \mathrm{Ks}>0.5\end{array}$ & $\begin{array}{l}\text { Orthologous pairs } \\
\text { with } \mathrm{Ka} / \mathrm{Ks}<0.1\end{array}$ \\
\hline $\mathrm{T1}$ & $\mathrm{T} 2$ & 12,688 & 2276 & 13 & 4 & 1575 & 684 \\
\hline T1 & T3 & 12,688 & 2452 & 15 & 6 & 1710 & 721 \\
\hline $\mathrm{T} 2$ & T3 & 12,688 & 1711 & 10 & 7 & 1180 & 512 \\
\hline
\end{tabular}

$\mathrm{T} 1, \mathrm{~T} 2$ and $\mathrm{T} 3$ indicate rabbiteye ( $V$. virgatum), southern highbush ( $V$. corymbosum $\times$ southern species), and northern highbush blueberry $(V$. corymbosum) species, respectively 

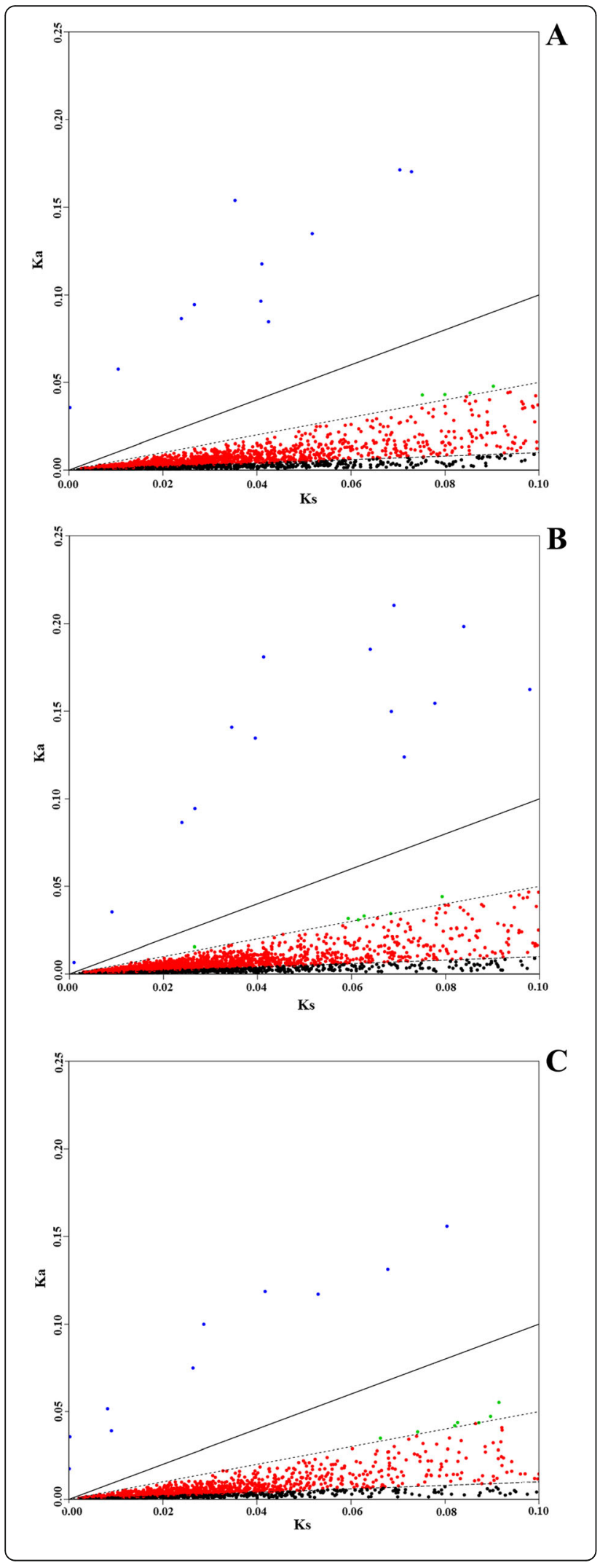

Fig. 3 Distribution of Ka/Ks values of single copy orthologs between three blueberry species. a $V$. virgatum $V s V$. conymbosum; $\mathbf{b} V$. virgatum $V_{s}$ ( $V$. corymbosum $\times$ southern species); $c$ : $V$. virgatum $V s$ ( $V$. corymbosum $\times$ southern species). $X$-axis indicates the value of Ka (Nonsynonymous substitution rate), Y-axis indicates the value of Ks (synonymous substitution rate) of single copy orthologs. Blue plots represent the single copy orthologs with $\mathrm{Ka} / \mathrm{Ks}$ more than 1 ; green plots represent the single copy orthologs with $\mathrm{Ka} / \mathrm{Ks}$ between 0.5 and 1; red plot represent the single copy orthologs with $\mathrm{Ka} / \mathrm{Ks}$ between 0.1 and 0.5 ; black plots represent the single copy orthologs with $\mathrm{Ka} / \mathrm{Ks}$ less than 0.1

excellent markers to study the phylogenetic relationship of diploid or polyploid individuals between intra- and inter-species [63, 64]. The sources of blueberry cultivars are complex, so clarifications by phylogenetic relationships are meaningful for the identification, protection and breeding of blueberry germplasm. Previous studies have used different molecular makers, including RAPD, SSR and SNP as a tool to construct the phylogenetic relationship of blueberry germplasm with different genetic origin [65-69]. In spite of the blueberry cultivars or breeding materials are from different origins or species with different ploidy levels, the SSR and SNPs marker seems to be an effective tool to differentiate and categorize blueberry cultivars $[65,67,69]$. Here, we used single copy nuclear gene dataset to reconstruct the phylogenetic relationships of three blueberry species, and detected a good differentiation and grouping of blueberry cultivars with different origins.

\section{Selection effects on single copy genes of T1, T2 and T3}

Whole genome duplication events occurred very commonly during the evolution of flowering plants [70]. However, some genes would return to single copy statue after suffering the duplication events, because one copy would lose randomly in the genome by genetic drift or duplication-resistant by dosage-sensitive selection in the next evolutionary process [71, 72]. In the recent years, single copy genes have attracted many researchers because of excellent application in genetics, for example, single copy gene is a good molecular tool to construct the phylogenetic tree of species [73]. Logically, without duplication copy, the single copy homologous genes could be regarded as orthologs, and paralogs don't disturb the evolutionary analysis, which made the single copy genes as the merit research object for the molecular mechanism of selection effect and speciation of organism [27, 34, 36, 55, 64, 73, 74]. In this study, we also only test the single copy unigenes to identify the molecular footprints of selection effects by using the method of $\mathrm{Ka} / \mathrm{Ks}$. In evolutionary genetics, Ks indicates synonymous substitute rate, and $\mathrm{Ka}$ indicates nonsynonymous substitute rate of protein coding genes. It is generally presumed that synonymous mutations are not subjected to natural selection, while non-synonymous 


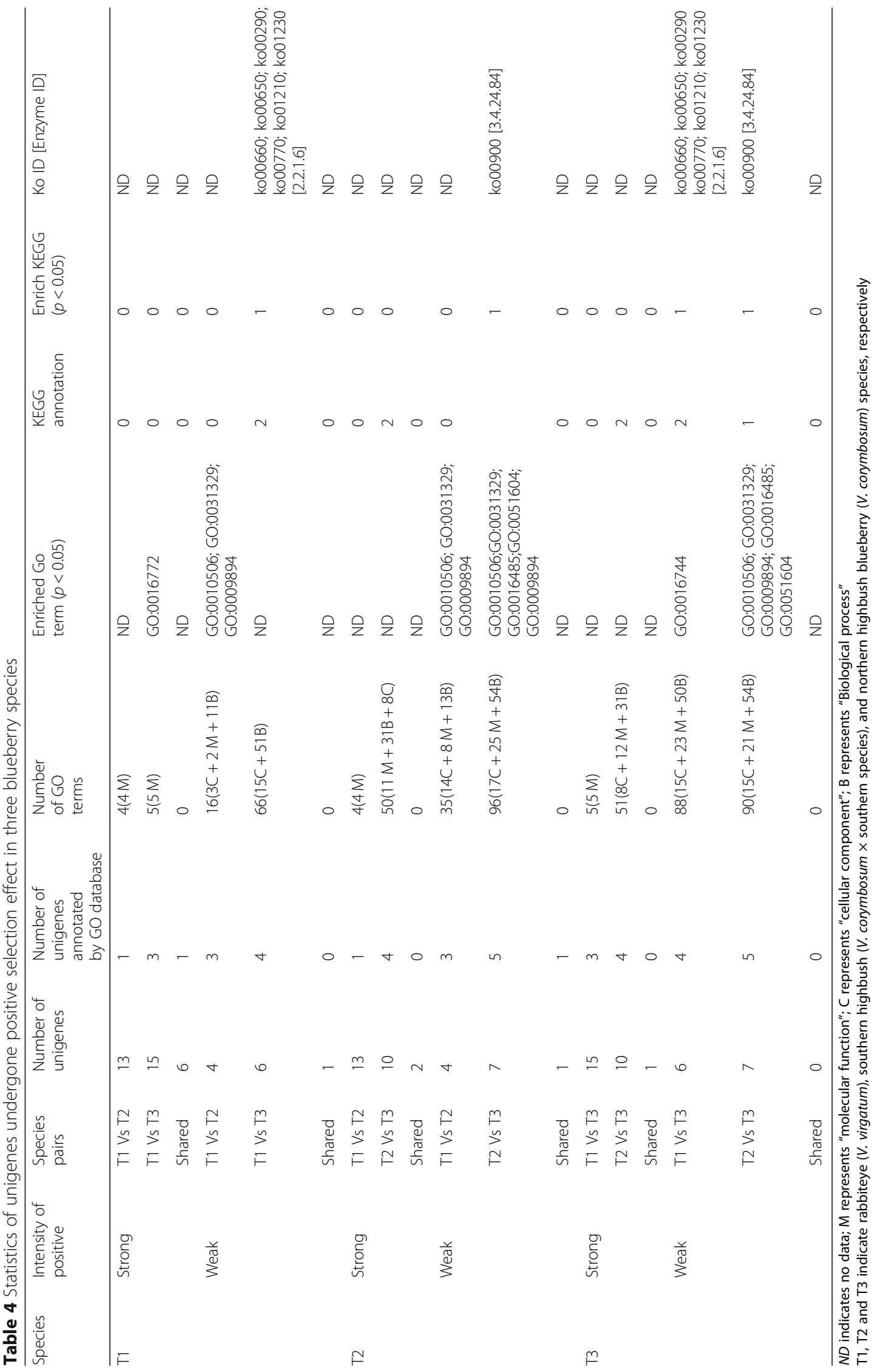




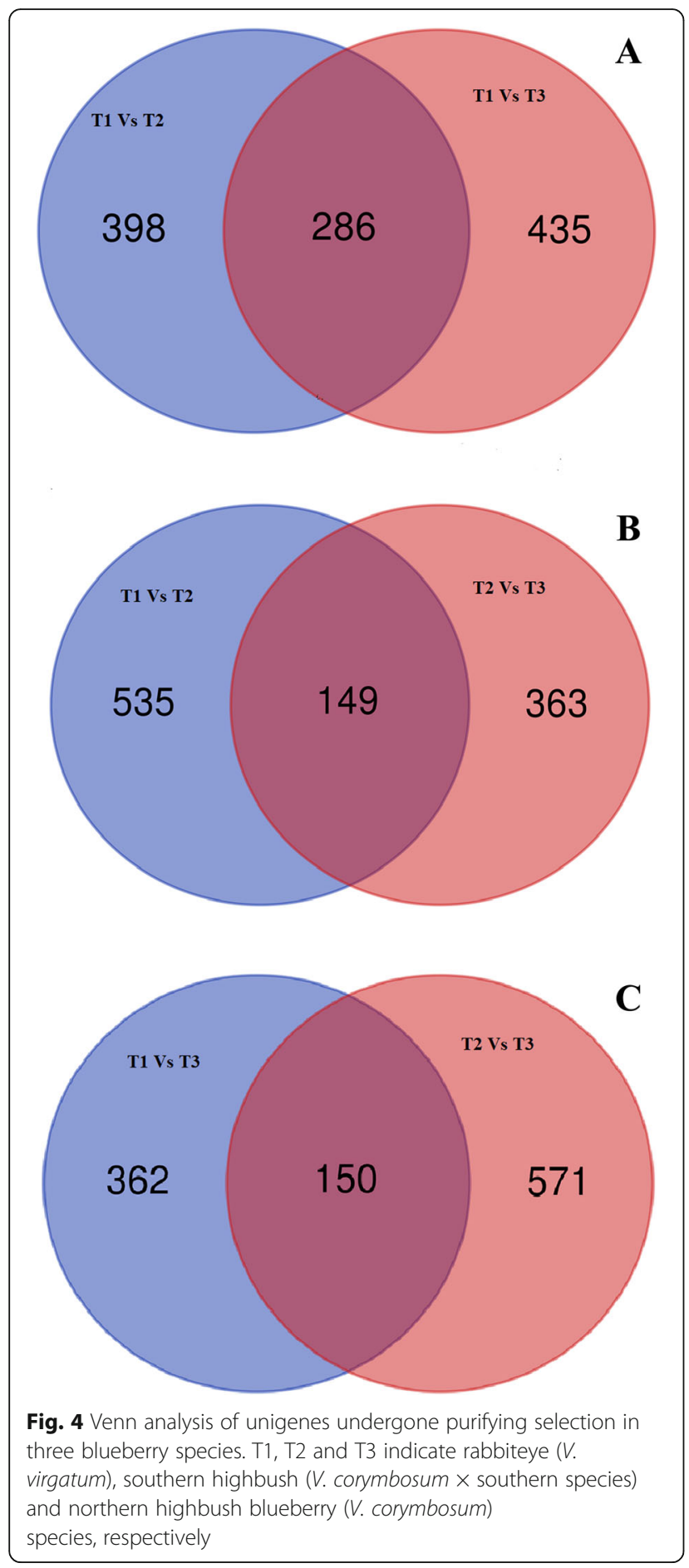

mutations would be subjected to natural selection for the change of structure and function led by the amino acid composition change in a coding protein [75]. $\mathrm{Ka} / \mathrm{Ks}$ indicates the ratio of mutations that change a specific protein structure and do not change a specific protein, and the value gives a clear idea to judge the evolutionary dynamics of orthologous protein-coding sequences across closely related and yet diverged species [76, 77].
Theoretically, it is thought that $\mathrm{Ka} / \mathrm{Ks}=1$ indicates the protein coding genes under neutral evolution, $\mathrm{Ka} / \mathrm{Ks}>1$ represents more non-synonymous substitutions occurred in orthologs, and suggesting that the genes evolved under positive selection, and $\mathrm{Ka} / \mathrm{Ks}<1$ indicates that the deleterious substitutions are eliminated by purifying selection (negative selection). But in empirical research, most genes with $\mathrm{Ka} / \mathrm{Ks}>0.5$ have undergone adaptive evolution by combining with Tajima'test, and $\mathrm{Fu} \& \mathrm{Li}$ test, and so the threshold of $\mathrm{Ka} / \mathrm{Ks}>0.5$ was always regarded as positive selection [78-81]. In this study, we followed the previous criteria and set $1>\mathrm{Ka} / \mathrm{Ks}>0.5$ as weak positive selection, and $\mathrm{Ka} / \mathrm{Ks}>1$ as strong positive selection. We also filtered the candidate orthologs with Ks value $>0.1$, as these may be paralogs as described by Zhang et al. [78] and Zhou et al. [82]. Our results revealed that most of the single copy unigenes evolved through neutral pattern. Besides, some single copy unigenes undergone negative selection, and their numbers were far more than that undergone positive selection (Table S2). This result illustrated that the occurrence of harmful mutations is more frequent than that of beneficial mutations in blueberry genome. Among unigenes undergone positive selection effect, we identified one ortholog (T2-Unigene0000660 and T3-Unigene0000319) that encoded "disease resistance protein RPS2", and involved into metabolic pathway "Plant-pathogen interaction (ko04626)" (Table S4). We speculated that this ortholog is a merit candidate gene for the breeding and improvement of blueberry cultivars and their ecological adaptation. According to our knowledge, this is the first report about the blueberry genome or gene selection effect in three species.

\section{Whole genome duplication in evolutionary history of blueberry}

The advent of plant genomics era has revealed the importance and ubiquity of WGD or polyploidy in the evolutionary history of species [83], because ancient WGD events could be conveniently and accurately reconstructed by using Ks age distribution analysis, or by detecting and comparative analysis of the collinear regions of intra- and inter-genome, or by constructing the molecular phylogenetic tree based on high throughput genome data [84]. Ks age distribution analysis has some significant merits including relatively low computational cost, available in the limited part of paranome, e.g. based on EST collections and no requirement of positional information on the paralogs, and was used frequently in the detection of WGD events [85]. Therefore, in this study, we also used Ks age distribution analysis to deduce the WGD event in the evolutionary history of T1, T2 and T3.

Ren et al. (2018) [35] detected the widely WGD events by using 105 genome/transcriptome data of different 

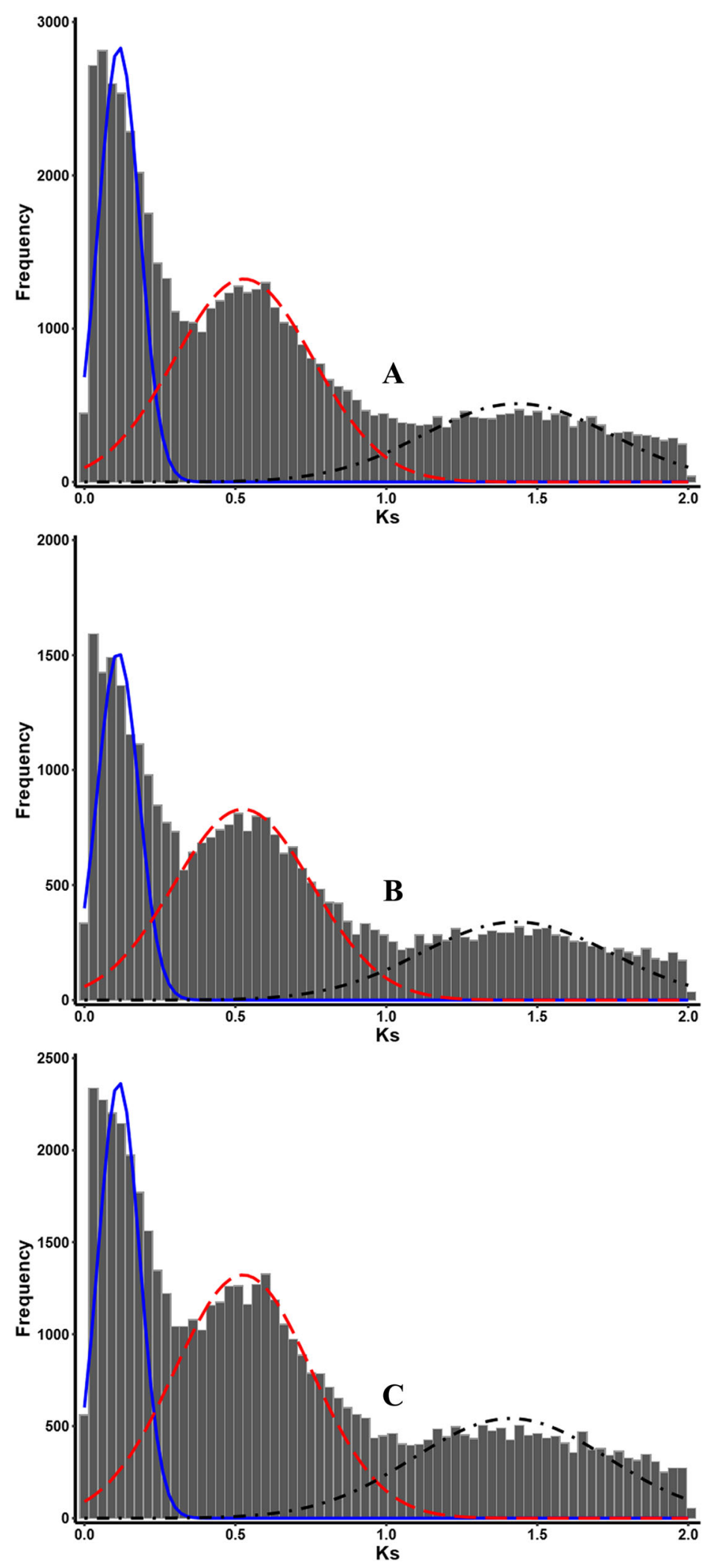

Fig. $5 \mathrm{Ks}$ age distribution of paralogs in three blueberry species. a $V$. virgatum; $\mathbf{b}(V$. corymbosum $\times$ southern species) $V$. corymbosum; c $V$. corymbosum. $\mathrm{X}$-axis indicates the Ks (synonymous substitution rate) value of paralogous, $Y$-axis indicates the number of paralogous for a specific Ks value range 
Table 5 The average value $(\mu)$ and standard deviation $(\sigma)$ of normal distribution peaks of fitted curve based on Ks age distribution

\begin{tabular}{llll}
\hline Species & The recent peak & The median peak & The oldest peak \\
\hline T1 & $0.1144 \pm 0.0678$ & $0.5281 \pm 0.2294$ & $1.4347 \pm 0.3103$ \\
T2 & $0.1113 \pm 0.0681$ & $0.5250 \pm 0.2283$ & $1.4298 \pm 0.31298$ \\
T3 & $0.1138 \pm 0.0687$ & $0.5255 \pm 0.2270$ & $1.4118 \pm 0.32068$ \\
\hline
\end{tabular}

$\mathrm{T} 1, \mathrm{~T} 2$ and $\mathrm{T} 3$ indicate rabbiteye $(V$. virgatum), southern highbush $(V$. corymbosum $\times$ southern species), and northern highbush blueberry $(V$. corymbosum) species, respectively

seed plant species including $V$. corymbosum, and made a conclusion that WGDs are commonly found in speciesrich lineages of eukaryotes. However, they did not find WGD events in $V$. corymbosum based on the transcriptome data. $V$. corymbosum (T2) are polyploid species as well as T1 and T3 [40], so the recent or new WGD events in the evolution history of T1, T2 and T3 should be detected. Colle et al. (2019) [49] deduced that a very recent polyploidization event occur in $V$. corymbosum approximately 69 to 77 thousand years ago based on the Ks divergence between homologs in highbush blueberry and the pair-wise LTR difference of $0.18-0.20 \%$ between the four haplotypes. However, whether this polyploidization event shared by other blueberry species is still unknown. In this study, even though the Ks age distribution histogram were not completely consistent from different transcriptome of three blueberry species, we detected three significant peaks with normal distribution in three blueberry species. Based on the fitting normal distribution curve, the median Ks value and standard deviation of first peak in T1, T2 and T3 were almost same, and similar trends were followed by second and third peaks. So, according to the histogram of $\mathrm{Ks}$ age distribution constructed by each paralogs dataset of $\mathrm{T} 1, \mathrm{~T} 2$ and $\mathrm{T} 3$, we deduced that at least three rounds of WGD events occur in the evolutionary history of blueberry species. The recent WGD event was found to occur approximately 9.04 million years ago before differentiation of three blueberry species, even might be before the differentiation of section Cyanococcus, which included about 20 species and most of them are polyploid, because all three WGD event shared by three species, and this WGD event might have played an important role in the speciation and evolution of Cyanococcus species. Vaccinium is species rich genus that comprised of about 450 species [38]. The polyploidization event is the important dynamics for plant species diversification $[11,86]$. So, the second WGD event, about 43.44 million years old, may have contributed greatly to the speciation of genus Vaccinium. In this study, we also detected an ancient WGD event about 116.39 million years old, and this was in accordance with the paleohexaploidization event $(\gamma)$ shared by the eudicots $[86,87]$. The difference in median Ks value between three blueberry species and other species can be explained by different substitution rates among the different plant lineages $[86,88,89]$. The results offer clear molecular footprints of three rounds of WGD events that occurred in the history of blueberry species, and it is helpful for understanding the molecular mechanism of complex evolutionary of blueberry species, even linages of Ericaceae.

\section{Conclusion}

Single copy nuclear gene dataset displayed a good differentiation and grouping of blueberry cultivars with different origins. Some important functional genes undergone positive selection in blueberry, and showed an adaptive evolution pattern. At least three rounds of WGD events were detected in the evolutionary history of blueberry species. Our work provides insights about the genetic mechanism of adaptive evolution in blueberry and species radiation of Vaccinium in short geological scale time.

\section{Methods \\ Identification of putative protein coding sequences from blueberry transcriptome}

A total of 45,535, 42,914 and 43,630 unigenes assembled from the leave's transcriptomes of 19 rabbiteye, 13 southern highbush and 22 northern highbush blueberry cultivars (Accession ID in Genbank: PRJNA511922) were analyzed as a basic data in this article. The samples information, construction of library, sequencing and assembling of unigenes had been published and described previously [55]. In short, 2-3 years old seedlings of 54 blueberry cultivars (information listed in Fig.2) were collected from blueberry germplasm nursery of Majiang Blueberry Industry Engineering Technology Center (Wuyangma village, Xuanwei town, Majiang county, Guizhou province, China), and total RNA was extracted from young leaves by total RNA kit (STRN50$1 \mathrm{KT} \mid$ Sigma) and strictly followed the guidelines provided by the company. The RNA-sequencing libraries were prepared as follow: Firstly, the total RNA was treated with DNAse and then poly-T-oligo-attached magnetic beads was used to filter poly-A-containing mRNA from the total RNA. Secondly, about $300 \sim 500$ base length fragments were obtained from the purified mRNA sequences, and the first single strand of cDNA was produced by using these fragments as template, and then second strand of cDNA was produced from the first strand of cDNA. Then, a 15 -cycle-PCR reaction was used to finalize sequencing library of the quantified and purified double strands. Finally, Illumina HighSeq 4000 platform was used for paired-end sequencing. Then, Trinity was used to assemble high-quality clean reads $(\geq Q 20)$ into unigenes with default parameters [90].

In this study, we identified all the putative protein coding sequences from aforementioned unigenes for further 
analysis. First, we blastx (ftp://ftp.ncbi.nlm.nih.gov/blast/ executables/blast+/LATEST/) the unigenes sequence with the databases according to the priority order of $\mathrm{Nr}$ (http://www.ncbi.nlm.nih.gov), Swiss-Prot (http://www. expasy.ch/sprot), KEGG [18] and COG/KOG [91] (Evalue cutoff level of $<1 \mathrm{E}-5)$. Unigene sequences were aligned stepwise with protein sequences in the databases following the aforementioned order. The iterative process goes on unless a significant match is found in the current database. After that, we selected the highest rank protein from the blast alignment results to determine the coding region sequence of the unigenes, and then translated the coding sequence into amino acid sequence according to the standard codon table, so as to obtain the nucleic acid sequence (sequence direction $5^{\prime}$ $>3^{\prime}$ ) and amino acid sequence of the coding region of unigene. Finally, we predict coding region (nucleic acid sequence with direction $5^{\prime}->3^{\prime}$ ) and corresponding protein sequence of unigenes that was aligned with above four databases by using program ESTScan [92]. Only those unigenes annotated by Nr, Swiss-Prot, KEGG and COG/KOG database or predicted coding region with program ESTScan were used for further analysis.

\section{Prediction of coding sequences and gene families}

The unigenes annotated or predicted coding region by program ESTScan were pairwise aligned with Blastp software [93]. After the alignment, the pairwise unigenes with Evalue lower than $1 \mathrm{E}-7$ were regarded as homologous unigenes of intra- or inter-species. Then, unigenes, homologs (i.e. orthologs and paralogs) to each other, were classified into the same gene family by using OrthoMCL software v2.0.9 with default parameters (identity, coverage) [94]. The gene families with more than one unigene in any transcriptome of three blueberry species were regarded as multiple copy gene families, otherwise regarded as single copy gene family. The gene families with unigenes only from one blueberry species were defined as species-specific genes families. Meanwhile, homologous or unique gene or gene families were also obtained, and the number of gene families and corresponding unigenes number of three blueberry species were then counted and analyzed by Venny tool (https://bioinfogp.cnb.csic.es/tools/venny/).

\section{Phylogenetic tree construction with single copy unigenes}

We clarified the genetic relationship of blueberry cultivars by constructing the molecular evolutionary tree based on single-copy homologous genes. First, we separately aligned all single copy unigenes families of three kinds of blueberry by program ClustalW (https://www.genome.jp/ tools-bin/clustalw). Second, the multiple sequence alignment of all single-copy gene families were joined together to obtain the total single-copy gene sequence files for the construction of evolutionary tree. Finally, the phylogenetic tree was constructed by using the neighbor joining $(\mathrm{NJ})$ method with 1000 iterations of MEGA software (https:// www.megasoftware.net/), and the nucleotide substitute rate was regarded as the evolutionary unit of branch length in the phylogenetic tree.

\section{$\mathrm{Ka} / \mathrm{Ks}$ test of single copy unigenes}

We aligned protein sequences of single copy homologous unigenes of three kinds of blueberries by using the software muscle (http://www.drive5.com/muscle) implemented in MEGA10.1 software (https://www.megasoftware.net/). The aligned sequences were converted to corresponding nucleotide sequences by using RevTrans 1.4 [95]. Nonsynonymous substitution rate (Ka), synonymous substitution rate (Ks) of T1, T2, and T3, and Ka/Ks of all single copy homologous gene pairs (orthologs) of T1 versus T2, T1 versus T3, and T2 versus T3 were estimated by KaKs_Calculator Toolbox with the standard genetic code table (version 2.0) [7]. We filtered the single copy orthologs with no applicable values of $\mathrm{Ka}$ or $\mathrm{Ks}$ or $\mathrm{Ks}$ values $>0.1$ (the benchmark of potential paralogs) as done by previous reports $[74,78,96]$. The validity of the Ka and Ks values were justified by Fisher's exact test as described by Zhou et al. (2016) [82], and positively or negatively selected sites were allowed when $\mathrm{P}$ was $<0.05$ and posterior probability was $>0.95$ based on the results of Chi-square test as performed by Yang \& Bielawski (2000) [97] and $\mathrm{Hu}$ et al. (2018) [79]. The low values of $\mathrm{Ka} / \mathrm{Ks}$ for most of the non-synonymous mutations are harmful, and single-copy homologous gene make organisms less tolerant to harmful mutations because they have no copies. So, in order to find out the unigenes which underwent positive selection but might be neutralized (or covered) by a large number of harmful mutant sites, we defined single copy orthologs with $\mathrm{Ka} / \mathrm{Ks}>1$ as strong positive selection, the $\mathrm{Ka} / \mathrm{Ks}$ values between 0.5 and 1 as weak positive selection, and with $\mathrm{Ka} / \mathrm{Ks}<0.1$ as negatively selected (purifying selection) according to previous reports [74, 79-81]. GO and KEGG enrichment analyses were performed by using GOseq [98] and KOBAS [99] of the orthologs sets with strong positive, weak positive and negative positive selection in three blueberry species, respectively. The $p$-value formula of the hypothesis test for significant enrichment was as follow:

$$
P=1-\sum_{i=0}^{m-1} \frac{\left(\begin{array}{c}
M \\
i
\end{array}\right)\left(\begin{array}{c}
N-M \\
n-i
\end{array}\right)}{\left(\begin{array}{c}
N \\
n
\end{array}\right)}
$$

Here, $\mathrm{N}$ is the number of genes with pathway (or GO) annotation in all unigenes; $\mathrm{n}$ is the number of species specific genes in N; $\mathrm{M}$ is the number of genes with a specific pathway (or GO) annotation in all unigenes; $m$ is the number of genes with a specific pathway (or GO) 
annotation. The calculated $P$-value was further corrected by Bonferroni test, and the KEGG pathway (or GO term) with $p$-value $<0.05$ was defined as the significantly enriched GO term (or GO term) for the species specific genes.

\section{Ks age distribution of duplicated unigene pairs (paralogs)}

We identified the duplicated unigenes pairs (paralogs) of each blueberry crop from the coding sequence (cds) with $40 \%$ sequence similarity for at least $300 \mathrm{bp}$ by the measure of discontinguous all-against-all MegaBLAST [100, 101]. We used the software muscle (http://www.drive5.com/ muscle) to align the protein sequences of paralogs, and the aligned sequences were then converted to corresponding nucleotide sequences by using RevTrans 1.4 [61]. We calculated the Ks of all paralogs of each blueberry crop by using the KaKs_Calculator Toolbox with the standard genetic code table (version 2.0) [95]. To avoid the effects of Ks saturation that produced the multiplicative effects from multicopy gene families, we filtered the paralogs with Ks $>2$ as done by Shi et al. [32]. We constructed the histogram of Ks density (age) distribution with bandwidth of 0.03 for each plot, and fitted a normal distribution curve with the Gaussian mixture model by mixtools program which built in R software [102]. We inferred the age of a duplication event by using the formula $\mathrm{T}_{\text {diversity }}=K s / 2 \mathrm{r}$ as described by Zhang et al. (2019b) [103]. We set the plant average $K s /$ year rate $=6.1 \times 10^{-9}$ for estimating the age of WGDs in blueberry species and median Ks value of each peak was used to determine the age of WGDs according to Lynch \& Conery (2000) [104].

\section{Supplementary information}

Supplementary information accompanies this paper at https://doi.org/10. 1186/s12870-020-02461-w.

\section{Additional file 1: Table S1. Statistics of unigenes undergone selection effect in three blueberry species. \\ Additional file 2: Table S2. Annotation summary of unigenes undergone positive selection.}

Additional file 3: Table S3. GO enrichment summary of unigenes undergone positive selection in three blueberry species.

Additional file 4: Table S4. KEGG enrichment summary of unigenes undergone positive selection in three blueberry species.

\section{Abbreviations}

WGD: Whole genome duplication; T1: Rabbiteye blueberry; T2: Southern highbush blueberry; T3: Northern highbush blueberry; MYA: Million years ago

\section{Acknowledgements}

Authors are thankful to lab members for assistance in study.

\section{Authors' contributions}

WYS conceived and designed the experiments. WYS, MQS, FSB and NF wrote the paper. WYS and NF performed the experiment. WYS and MQS analyzed the data. All authors read and approved the final version of manuscript.

\section{Funding}

This work was funded by the key project of the Education Department of Guizhou Province [KY(2013)186], Science Department of Guizhou Province [(2015)6013] and [(2016)5202] and the National Natural Science Foundation of China [31560091]

\section{Availability of data and materials}

The datasets generated and/or analysed during the current study are available in the Genbank (Accessible ID: PRJNA511922) [NCBI] repository, Link: https://www.ncbi.nlm.nih.gov/search/all/?term=PRJNA511922, and the datasets used and/or analysed during the current study available from the corresponding author on reasonable request.

\section{Ethics approval and consent to participate}

Plant samples used in the study were not collected from national park or natural reserve. According to national and local legislation, no specific permission was required for collecting these plants. We confirm that this complies with national guidelines and no formal ethics approval was required in this particular case.

\section{Consent for publication}

Not applicable.

\section{Competing interests}

The authors declare that they have no competing interests.

\section{Author details}

${ }^{1}$ College of Health and Life Science, Kaili University, Kaili City 556011, Guizhou Province, China. ${ }^{2}$ Biological institute of Guizhou Province, Guiyang City 556000, Guizhou Province, China. ${ }^{3}$ State Key Laboratory for Conservation and Utilization of Subtropical Agro-Bioresources, South China Agricultural University, Guangzhou 510642, China. ${ }^{4}$ Guangdong Provincial Key Laboratory of Plant Molecular Breeding, South China Agricultural University, Guangzhou 510642, China. ${ }^{5}$ College of Agriculture, South China Agricultural University, Guangzhou 510642, Guangdong Province, China. ${ }^{6}$ Department of Field Crops, Faculty of Agricultural and Natural Sciences, Abant İzet Baysal University, Bolu, Turkey.

Received: 28 December 2019 Accepted: 24 May 2020

Published online: 03 June 2020

\section{References}

1. Basener WF, Sanford JC. The fundamental theorem of natural selection with mutations. J Math Biol. 2018;76:1589-622.

2. Hurst LD. Genetics and the understanding of selection. Nat Rev Genet. 2009; 10:83-93.

3. Feder AF, Kryazhimskiy S, Plotkin JB. Identifying signatures of selection in genetic time series. Genetics. 2014;196(2):509-22.

4. Zhai W, Neilsen R, Slatkin M. An investigation of the statistical power of neutrality tests based on comparative and population genetic data. Mol Biol Evol. 2009:26(2):273-83.

5. Vitti JJ, Grossman SR, Sabeti PC. Detecting natural selection in genomic data. Annu Rev Genet. 2013;47:97-120.

6. Hurst LD. The Ka/Ks ratio: diagnosing the form of sequence evolution. Trends Genet. 2002;18:486.

7. Zhang Z, Li J, Zhao X, Wang J, Wong GK, Yu J. KaKs_calculator:calculating Ka and Ks through model selection and model averaging. Genomics Proteomics Bioinformatics. 2006:4(4):259-63.

8. Du MZ, Liu S, Zeng Z, Alemayehu LA, Wei W, Guo FB. Amino acid compositions contribute to the proteins' evolution under the influence of their abundances and genomic GC content. Sci Rep. 2018;8:73-82.

9. Kellis M, Birren BW, Lander ES. Proof and evolutionary analysis of ancient genome duplication in the yeast Saccharomyces cereviseae. Nature. 2004; 428:617-24.

10. Doyle JJ, Flagel LE, Paterson AH, Rapp RA, Soltis DE, Soltis PS, Wendel JF. Evolutionary genetics of genome merger and doubling in plants. Annu Rev Genet. 2008;42:443-61.

11. Soltis DE, Albert VA, Leebens-Mack J, Bell CD, Paterson AH, Zheng C, Sankoff D, de Pamphilis C, Wall PK, Soltis PS. Polyploidy and angiosperm diversification. Am J Bot. 2009;96:336-48. 
12. Vanneste K, Maere S, Peer $\mathrm{Y}$. Tangled up in two: a burst of genome duplications at the end of the cretaceous and the consequences for plant evolution. Phil Trans R Soc B. 2014a;369:20130353.

13. Edger PP, Heidel-Fischer HM, Bekaert M, Rota J, Glöckner G, Platts AE, Heckel DG, Der JP, Wafula EK, Tang M, et al. The butterfly plant armsrace escalated by gene and genome duplications. Proc Natl Acad Sci U S A. 2015;112:8362-6.

14. Tank DC, Eastman JM, Pennell MW, Soltis PS, Soltis DE, Hinchliff CE, Brown JW, Sessa EB, Harmon LJ. Nested radiations and the pulse of angiosperm diversification: increased diversification rates often follow whole genome duplications. New Phytol. 2015;207:454-67.

15. Soltis PS, Soltis DE. Ancient WGD events as drivers of key innovations in angiosperms. CurrOpin Plant Biol. 2016;30:159-65.

16. Landis JB, Soltis DE, Zheng L, Marx HE, Tank D, Barker MS, Soltis PS. Impact of whole genome duplication events on diversification rates in angiosperms. Am J Bot. 2018;105:433-44.

17. Soltis PS, Folk RA, Soltis DE. Darwin review: angiosperm phylogeny and evolutionary radiations. Proc R Soc B. 2019;286:20190099.

18. Kihara H, Ono T. Chromosomen-zahlen und systematische Gruppierung der Rumex-Arten. Z Zellforsch Mikr Anat. 1926:4:475-81.

19. Ramsey J, Schemske DW. Pathways, mechanisms, and rates of polyploidy formation in flowering plants. Annu Rev Ecol Syst. 1998;29:467-501.

20. Barker MS, Arrigo N, Baniaga AE, Li Z, Levin DA. On the relative abundance of auto- and allopolyploids. New Phytol. 2016;210:391-8.

21. Zhang L, Shivute FN, Shahid MQ, Kamara N, Wu J, Liu X. In vitro induction of auto allotetraploid in a newly developed wild rice line from Oryza alta Swallen. Plant Cell Tissue Organ Culture. 2019a:139:577-87.

22. Vanneste K, Baele G, Maere S, Van de Peer Y. Analysis of 41 plant genomes supports a wave of successful genome duplications in association with the cretaceous-Paleogene boundary. Genome Res. 2014b;24:1334-47.

23. Jiao Y, Wickett NJ, Ayyampalayam S, Chanderbali AS, Landherr L, Ralph PE, Tomsho LP, Hu Y, Liang H, Soltis PS, et al. Ancestral polyploidy in seed plants and angiosperms. Nature. 2011;473:97-100.

24. Wolfe KH. Yesterday's polyploids and the mystery of diploidization. Nat Rev Genet. 2001;2:333-41.

25. Hufton AL, Panopoulou G. Polyploidy and genome restructuring: a variety of outcomes. Curr Opin Genet Dev. 2009;19:600-6.

26. Zakas C, Schult N, McHugh D, Jones KL, Wares JP. Transcriptome analysis and SNP development can resolve population differentiation of streblospio benedicti, a developmentally dimorphic marine annelid. PLoS One. 2012; 7(2):e31613.

27. Yang $Y$, Li X, Kong $X$, Ma L, Hu X, Yang Y. Transcriptome analysis reveals diversified adaptation of Stipa purpurea along a drought gradient on the Tibetan plateau. Funct Integr Genomics. 2015a;15(3):295-307.

28. Delsuc F, Philippe $H$, Tsagkogeorga $G$, et al. A phylogenomic framework and timescale for comparative studies of tunicates. BMC Biol. 2018;16:39.

29. Wheat CW. Rapidly developing functional genomics in ecological model systems via 454 transcriptome sequencing. Genetica. 2010;138: 433-51.

30. Duffy K. A blueberry-enriched diet provides cellular protection against oxidative stress and reduces a kainate-induced learning impairment in rats. Neurobiol Aging. 2008;29(11):1680-9.

31. Dewit P, Pespeni MH, Palumbi SR. SNP genotyping and population genomics from expressed sequences - current advances and future possibilities. Mol Ecol. 2015;24:2310-23.

32. Shi T, Huang $H$, Barker MS. Ancient genome duplications during the evolution of kiwifruit (Actinidia) and related Ericales. Ann Bot. 2010; 106:497-504

33. Zhang L, Yan HF, Wu W, Yu H, Ge XJ. Comparative transcriptome analysis and marker development of two closely related primrose species (Primula poissonii and Primula wilsonii). BMC Genomics. 2013a;14(1):329.

34. Qiao Q, Wang Q, Han X, Guan Y, Sun H, Zhong Y, Huang J, Zhang T. Transcriptome sequencing of Crucihimalaya himalaica (Brassicaceae) reveals how Arabidopsis close relative adapt to the Qinghai-Tibet plateau. Sci Rep. 2016;6:21729.

35. Ren R, Wang H, Guo C, Zhang N, Zeng L, Chen Y, Ma H, Qi J. Wide-spread whole genome duplications contribute to genome complexity and species diversity in angiosperms. Mol Plant. 2018;11(3):414-28.

36. Ren $Y$, Zhu Y, Wang Q, Xiang H, Wang B. Transcriptome of Pterospermum kingtungense provides implications on the mechanism underlying its rapid vegetative growth and limestone adaption. Sci Rep. 2017;7:3198.
37. Kron KA, Judd WS, Stevens PF, Crayn DM. Anderberg AA,5 Gadek PA, Quinn CJ, Luteynj L. phylogenetic classification of Ericaceae: molecular and morphological evidence. Bot Rev. 2002;68(3):335-423.

38. Mabberley DJ. The Plant-Book: A Portable Dictionary of the Vascular Plants. 2nd ed. Cambridge: Cambridge University Press; 1997. p. 740.

39. Song QS, Hancock JF. Recent advances in blueberry transformation. Int J Fruit Sci. 2012;12:316-32

40. Lyrene PM, Vorsa N, Ballington J. Polyploidy and sexual polyploidization in the genus Vaccinium. Euphytica. 2003;133(1):27-36.

41. Hancock JF, Lyrene P, Finn CE, Vorsa N, Lobos GA. Blueberries andcranberries. In: Hancock JF, editor. Temperate fruit crop breeding. New York: Springer; 2008. p. 115-49.

42. USDA National Agricultural Statistics Service (2017) Noncitrus fruits and nuts 2016 summary. http://usda.mannlib.cornell.edu/usda/current/NoncFruiNu/ NoncFruiNu-06-27-2017.pdf. Accessed 3 Oct 2017.

43. Cho E, Seddon JM, Rosner B, Willett WC, Hankinson SE. Prospective study of intake of fruits, vegetables, vitamins, and carotenoids and risk of age-related maculopathy. Arch Ophthalmol. 2004;122:883-92.

44. Kalt W, Joseph JA, Shukitt-Hale B. Blueberries and human health: a review of the current research. J Am Pomol Soc. 2007;61:151-60.

45. Rimando AM, Kalt W, Magee JB, Dewey J, Ballington JR. Resveratrol, pterostilbene, and piceatannol in Vaccinium berries. J Agric Food Chem. 2004;52:4713-9.

46. Galletta GL, Ballington JR. Bluberries, cranberries and lingonberries. In: Janick J, Moore JN, editors. Fruit breeding, vol. 2. New York: Wiley; 1996. p. 1-107.

47. Rowland LJ, Alkharouf NW, Darwish O, Ogden EL, Polashock JJ, Bassil L, Main D. Generation and analysis of blueberry transcriptome sequences from eaves, developing fruit, and flowers from cold acclimation through deacclimation. BMC Plant Biol. 2012;12:46.

48. Gupta V, Estrada AD, Blakley IC, Reid R, Patel K, Meyer MD, Andersen SU, Brown AF, Lila MA, Loraine AE. RNA-Seq analysis and annotation of a draft blueberry genome assembly identifies candidate genes involved in fruit ripening, biosynthesis of bioactive compounds, and stage-specific alternative splicing. GigaScience. 2015:4:5.

49. Colle M, Leisner CP, Wai CM, Ou S, Bird KA, Wang J, Wisecaver JH, Yocca AE, Alger $\mathrm{El}$, Tang $\mathrm{H}$, et al. Haplotype-phased genome and evolution of phytonutrient pathways of tetraploid blueberry. GigaScience. 2019;8(3). https://doi.org/10.1093/gigascience/giz012.

50. Rowland LJ, Panta GR, Mehra S, Parmentier-Line C. Molecular genetic and physiological analysis of the cold-responsive dehydrins of blueberry. J Crop Improv. 2004;10:53-76.

51. Dhanaraj AL, Alkharouf NW, Beard HS, Chouikha IB, Matthews BF, Wei H, Arora R, Rowland LJ. Major differences observed in transcript profiles of blueberry during cold acclimation under field and cold room conditions. Planta. 2007:225:735-51.

52. Rowland LJ, Dhanaraj AL, Naik D, Alkharouf N, Matthews B, Arora R. Study of cold tolerance in blueberry using EST libraries CDNA microarrays, and subtractive hybridization. HortScience. 2008;43:1975-81.

53. Li $X$, Sun H, Pei J, Dong Y, Wang F, Chen H, Sun Y, Wang N, Li H, Li Y. De novo sequencing and comparative analysis of the blueberry transcriptome to discover putative genes related to antioxidants. Gene. 2012;511(1):54-61.

54. Miles TD, Day B, Schilder AC. Identification of differentially expressed genes in a resistant versus a susceptible blueberry cultivar after infection by Colletotrichum acutatum. Mol Plant Pathol. 2011;12(5):463-7.

55. Wang YS, Shahid MQ, Ghouri F, Ercişli S, Baloch FS, Nie F. Transcriptome analysis and annotation: SNPs identified from single copy annotated unigenes of three polyploid blueberry crops. PLoS One. 2019a;14(4): e0216299.

56. Yuskianti V, Shiraishi S. Gentic diversity of sengon (Falcataria moluccana (Miq.) Barneby \& J.W. Grimes) revealed using sinlge nucletide polymorphism markers. Indones J Forest Res. 2017;4(2):85-94.

57. Foster J, Allan G, Chan A, Rabinowicz P, Ravel J, Jackson P, Keim P. Single nucleotide polymorphisms for assessing genetic diversity in castor bean (Ricinus communis). BMC Plant Biol. 2010;10:13.

58. Nadeem MA, Nawaz MA, Shahid MQ, Doğan $Y$, Comertpay G, Yıldız M, Hatipoğlu R, Ahmad F, Alsaleh A, Labhane N, et al. DNA molecular markers in plant breeding: current status and recent advancements in genomic selection and genome editing. Biotechnol Biotechnol Equip. 2018;32:261-85

59. Thomson MJ. High-throughput SNP genotyping to accelerate crop improvement. Plant Breed Biotechnol. 2014;2(3):195-212. 
60. Zhao Y, Wang K, Wang W, Yin T, Dong W, Xu C. A high-throughput SNP discovery strategy for RNA-seq data. BMC Genomics. 2019;20:160.

61. Lee TH, Guo H, Wang X, Kim C, Paterson AH. SNPhylo: a pipeline to construct a phylogenetic tree from huge SNP data. BMC Genomics. 2014;15:162

62. Ahmed SA, Lo CC, Li PE, Davenport KW, Chain PSG. From raw reads to trees: whole genome SNP phylogenetics across the tree of life. BioRxiv. 2015. https://doi.org/10.1101/032250.

63. Lu RS, Xu WQ, Lu QX, Li P, Losh J, Hina F, Li E, Qiu Y. Generation and classification of transcriptomes in two Croomia species and molecular evolution of CYC/TB1 genes in Stemonaceae. Plant Diversity. 2018;40(6):253-64.

64. Yi S, Zhou X, Li J, Zhang M, Luo S. Full-length transcriptome of Misgurnus anguillicaudatus provides insights into evolution of genus Misgurnus. Sci Rep. 2018:8:11699.

65. Burgher KL, Jamieson AR, Lu X. Genetic relationships among lowbush blueberry genotypes as determined by randomly amplified polymorphic DNA analysis. J Amer Soc Hort Sci. 2002;127(1):98-103.

66. Cui J, Liu H, Zou R, Liang Y, Li Y, Wen J. Study on genetic diversity and phylogenetic relationship of germplasm resources about Vaccinium spp. J Fruit Sci. 2010:27(3):373-8.

67. Rowland L, Ogden EL, Ehlenfeldt MK. EST-PCR markers developed for highbush blueberry are also useful for genetic fingerprinting and relationship studies in rabbiteye blueberry. Sci Hortic. 2010;125:779-84.

68. Bian Y, Ballington J, Raja A, Brouwer C, Reid R, Burke M, Wang X, Rowland $\sqcup$, Bassil N, Brown A. Patterns of simple sequence repeats in cultivated blueberries (Vaccinium section Cyanococcus spp.) and their use in revealing genetic diversity and population structure. Mol Breeding. 2014;34:675-89.

69. Campa A, Ferreira JJ. Genetic diversity assessed by genotyping by sequencing (GBS) and for phenological traits in blueberry cultivars. PLoS One. 2018;13(10):e0206361

70. Zhang J. Evolution by gene duplication: an update. Trends Ecol Evol. 2003; 18(6):292-8

71. Birchler JA, Riddle NC, Auger DL, Veitia RA. Dosage balance in gene regulation: biological implications. Trends Genet. 2005;21(4):219-26.

72. Edger PP, Pires JC. Gene and genome duplications: the impact of dosagesensitivity on the fate of nuclear genes. Chromosom Res. 2009;17(5):699-717.

73. Han Z, Ma X, Wei M, Zhao T, Zhan R, Chen W. SSR marker development and intraspecific genetic divergence exploration of Chrysanthemum indicum based on transcriptome analysis. BMC Genomics. 2018;19:29.

74. Lu RS, Xu WQ, Lu QX, et al. Generation and classification of transcriptomes in two Croomia species and molecular evolution of CYC/TB1 genes in Stemonaceae. Plant Diversity. 2018;40(6):253-64.

75. Dimitrieva S, Anisimova M. Unraveling patterns of site-to-site synonymous rates variation and associated gene properties of protein domains and families. PLoS One. 2014;9(6):e95034.

76. Hughes AL, Nei M. Pattern of nucleotide substitution at major histocompatibility complex class I loci reveals overdominant selection. Nature. 1988;335(6186):167-70.

77. Fay JC, $\mathrm{Wu} \mathrm{Cl}$. Sequence divergence, functional constraint, and selection in protein evolution. Annu Rev Genomics Hum Genet. 2003:4:213-35.

78. Zhang J, Xie P, Lascoux M, Meagher TR, Liu J. Rapidly evolving genes and stress adaptation of two desert poplars. PLoS ONE. 2013b;8:e66370.

79. Hu Q, Wang Q, Meng Y, Tian H, Xiao H. Comparative transcriptome reveal the potential adaptive evolutionary genes in Andrias davidianus. Hereditas. 2018;155:18

80. Swanson WJ, Wong A, Wolfner MF, Aquadro CF. Evolutionary expressed sequence tag analysis of drosophila female reproductive tracts identifies genes subjected to positive selection. Genetics. 2004;168(3):1457-65.

81. Ren L, Tan XJ, Xiong YF, Xu K, Zhou Y, Zhou H, Liu Y, Hong Y, Liu S. Transcriptome analysis reveals positive selection on the divergent between topmouth culter and zebrafish. Gene. 2014;552(2):265-71.

82. Zhou T, Chen C, Wei Y, Chang Y, Chang Y, Bai G, Li Z, Kanwal N, Zhao G Comparative transcriptome and chloroplast genome analyses of two related dipteronia species. Front Plant Sci. 2016;7:1512.

83. Hollister JD. Polyploidy: adaptation to the genomic environment. New Phytol. 2015;205:1034-9.

84. Van de Peer Y, Fawcett JA, Proost S, Sterck L, Vandepoele K. The flowering world: a tale of duplications. Trends Plant Sci. 2009;14:680-8.

85. Cui L, Wall PK, Leebens-Mack JH, Lindsay BG, Soltis DE, Doyle JJ, Soltis PS, Carlson JE, Arumuganathan K, Barakat A, ViA A, Ma H, de Pamphilis CW.
Widespread genome duplications throughout the history of flowering plants. Genome Res. 2006;16:738-49.

86. Soltis DE, Bell CD, Kim S, Soltis PS. Origin and early evolution of angiosperms. Ann N Y Acad Sci. 2008;1133:3-25.

87. Vekemans $D$, Proost $S$, Vanneste $K$, Coenen $H$, Viaene T, Ruelens $P$, Maere $S$, de Peer YV, Geuten K. Gamma paleohexaploidy in the stem lineage of core eudicots: significance for MADS-box gene and species diversification. Mol Biol Evol. 2012;29:3793-806.

88. Wang K, Wang Z, Li F, Ye W, Ye W, Wang J, Song G, Yue Z, Cong L, Shang $\mathrm{H}$, Zhu S, et al. The draft genome of a diploid cotton Gossypium raimondii. Nat Genet. 2012:44:1098-103.

89. Smith DR, Arrigo KR, Alderkamp AC, Allen AE. Massive difference in synonymous substitution rates among mitochondrial, plastid, and nuclear genes of Phaeocystis algae. Mol Phylogenet Evol. 2014;71:36-40.

90. Grabherr MG, Haas BJ, Yassour M, Levin JZ, Thompson DA, Amit I, et al. Fulllength transcriptome assembly from RNA-Seq data without a reference genome. Nature biotech. 2011;29(7):644-52.

91. Tatusov RL, Galperin MY, Natale DA, Koonin EV. The COG database: a tool for genome-scale analysis of protein functions and evolution. Nucleic Acids Res. 2000;28:33-6.

92. Iseli C, Jongeneel CV, Bucher P. ESTScan: a program for detecting, evaluating, and reconstructing potential coding regions in EST sequences. Proc Int Conf Intell Sys Mol Biol. 1999;99:138-48.

93. Stephen A, Gi W, Mi W, Eugene M, David L. Basic local alignment search tool. J Mol Biol. 1990;215(3):403-10.

94. Li L, Stoeckert CJ Jr. Roos DS OrthoMCL: identification of ortholog groups for eukaryotic genomes. Genome Res. 2003;13:2178-89.

95. Wernersson R, Pedersen AG. RevTrans: multiple alignment of coding DNA from aligned amino acid sequences. Nucleic Acids Res. 2003;31:3537-9.

96. Bustamante CD, Fledel-Alon A, Williamson S, Nielsen R, Hubisz MT, Glanowski S, Tanenbaum DM, White TJ, Sninsky JJ, Hernandez RD, et al. Natural selection on protein-coding genes in the human genome. Nature. 2005:437:1153-7.

97. Yang Z, Bielawski JP. Statistical methods for detecting molecular adaptation. Trends Ecol Evol. 2000:15(12):496.

98. Young MD, Wakefifield MJ, Smyth GK, Oshlack AJGB. Gene ontology analysis for RNA-seq: accounting for selection bias. Genome Biol. 2010;1 (2):R14.

99. Mao X, Cai T, Olyarchuk JG, Wei LJB. Automated genome annotation and pathway identification using the KEGG Orthology (KO) as a controlled vocabulary. Bioinformatics. 2005;21(19):3787-93.

100. Zhang Z, Schwartz S, Wagner L, Miller W. A greedy algorithm for aligning DNA sequences. J Comput Biol. 2000;7:203-14.

101. Ma B, Tromp J, Li M. PatternHunter: faster and more sensitive homology search. Bioinformatics. 2002:18:440-5.

102. Benaglia T, Chauveau D, Hunter DR, Young D. Mixtools: an R package for analyzing finite mixture models. J Stat Softw. 2009;32(6):1-29.

103. Zhang R, Wang FG, Zhang J, Shang H, Liu L, Wang H, Zhao GH, Shen H, Yan YH. Dating whole genome duplication in Ceratopteris thalictroides and potential adaptive values of retained gene duplicates. Int J Mol Sci. 2019b; 20:1926.

104. Lynch M, Conery JS. The evolutionary demography of duplicate genes. J Struct Funct Genom. 2000;3:35-44.

\section{Publisher's Note}

Springer Nature remains neutral with regard to jurisdictional claims in published maps and institutional affiliations.

Ready to submit your research? Choose BMC and benefit from:

- fast, convenient online submission

- thorough peer review by experienced researchers in your field

- rapid publication on acceptance

- support for research data, including large and complex data types

- gold Open Access which fosters wider collaboration and increased citations

- maximum visibility for your research: over $100 \mathrm{M}$ website views per year

At $\mathrm{BMC}$, research is always in progress.

Learn more biomedcentral.com/submission 